\title{
Estudo Prospectivo e Randomizado da Sonda Foley na Preparação do Colo Uterino Desfavorávelà Indução do Parto
}

Autor: Marcus Guazzelli Maurício de Oliveira

Orientador: Profa.Dra. Marilza Vieira Cunha Rudge

Dissertação de Mestrado apresentada ao Curso de Pós-Graduação em Ginecologia e Obstetrícia - Área de Concentração em Obstetrícia, da Faculdade de Medicina de Botucatu, UNESP, em 31 de março de 2003.

Objetivo: Avaliar a efetividade da sonda Foley intracervical por 12 horas, no amadurecimento do colo uterino desfavorável, comparando seu efeito no índice de Bishop e dilatação cervical. Foi um ensaio clínico, controlado não cego, com alocação aleatória do tratamento, realizado no Serviço de Obstetrícia (DGO), Faculdade de Medicina de Botucatu, UNESP.

Pacientes e Métodos: Foram incluídas 127 gestantes com colo desfavorável para indução do parto (indice de Bishop 5), gestação única e feto em apresentação cefálica: 64 submetidas à utilização da sonda Foley (grupo exposto) e 63 sem o uso da sonda Foley (grupo não exposto). A sonda Foley $n^{\circ} 22$ foi introduzida no colo uterino até ultrapassar o orifício interno, após antisepsia com povidine e o balão insuflado com $30 \mathrm{~mL}$ de soro fisiológico. Após 12 horas a sonda foi retirada e o índice de Bishop foi repetido pelo mesmo examinador, obtendo-se os índices de Bishop pré e pós-retirada da sonda Foley.
Resultados: O índice de Bishop pré-aplicação da sonda Foley foi semelhante nos dois grupos. As gestantes do grupo exposto à sonda Foley apresentaram indice de Bishop significativamente aumentado. O uso da sonda Foley alterou o indice de Bishop de 1 a 8 pontos em $95,2 \%$ das gestantes e, na ausência de tratamento, $85,9 \%$ das pacientes permaneceram com a mesma dilatação cervical. O risco relativo de obtenção de colo favorável com o uso da sonda Foley foi de 19,3 vezes, com intervalo de confiança de $95 \%$, variando de 4,86 a 76,6. Conclusões: O uso da sonda Foley intracervical aumentou significativamente o indice de Bishop de 3.0 para 6.0 em $95.2 \%$ dos casos e a dilatação cervical de 1.0 $\mathrm{cm}$ para $3.0 \mathrm{~cm}$. Aumentou em 19,3 vezes o risco relativo de obtenção de colo uterino favorável para indução do parto. Esta é uma alternativa eficaz para a preparação do colo uterino desfavorável à indução do parto.

Palavras-chave: Resolução da gravidez. Índice de Bishop. Trabalho de parto.

\section{Citologia Oncológica, Captura de Hibridos II e Inspeção Visual no Rastreamento de Lesões Pré-Neoplásicas e Neoplásicas Cervicais em uma Unidade Básica de Saúde de Campinas}

Autor: Renata Clementino Gontijo

Orientadora: Profa.Dra Sophie Francoise Mauricette Derchain

Dissertação de Mestrado apresentada ao Departamento de Tocoginecologia da Universidade Estadual de Campinas, no dia 06 de junho de 2003.

Objetivo: avaliar o desempenho da citologia oncológica (CO), captura híbrida II (CH II) e inspeção visual com ácido acético (IVA) na detecção de lesões cervicais. Métodos: Foram incluídas 684 mulheres que responderam a um questionário e foram submetidas a coleta do exames. Foram comparadas as mulheres com resultado de exame positivo e negativo e as caracteristicas sociodemográficas e reprodutivas, utilizando-se a análise multivariada. Foram calculadas sensibilidade, especificidade, e valores preditivos positivo e negativo e seus respectivos IC a 95\%, utilizando-se como padrão-ouro a colposcopia.

Resultados: setenta e uma $(10,4 \%)$ mulheres apresentaram CO alterada, a CH II foi positiva em 131 (19,2\%), e em $55(8 \%)$ a IVA foi anormal. Em 198 mulheres pelo menos um teste foi alterado; 48 faltaram ao retorno e não foram submetidas a colposcopia. Entre as 150 mulheres que fizeram colposcopia, 91 não apresentaram imagem suspeita. Das mulheres biopsiadas, 38 apresentaram cervicite, 10 NIC1, 10 NIC2/3 e um carcinoma. Observamos que iniciar a atividade sexual com menos de 18 anos e ter mais que um parceiro no último ano foram fatores associados com a presença de exames alterados. Apenas o fato de nunca ter realizado citologia esteve associado a presença de doença. A sensibilidade dos testes foi semelhante, a especificidade da IVA e da $\mathrm{CO}$ foi maior que a da $\mathrm{CH}$ II.

Conclusão: a detecção de doença foi baixa. Embora algumas características da população estiveram associadas com a positividade dos exames, apenas a realização de CO prévia associou-se com ausência de doença. Nos casos com CO negativo, a IVA apresentou melhor desempenho que a $\mathrm{CH}$ II. 